\title{
INVESTIGATION OF TADF PROPERTIES OF NOVEL DONOR-ACCEPTOR TYPE PYRAZINE DERIVATIVES
}

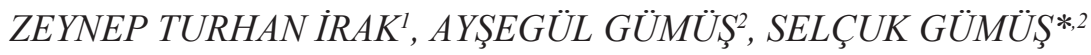

${ }^{1}$ Igdir University, Engineering Faculty, Environmental Engineering Department, Igdir, Turkey.

${ }^{2}$ Van Yuzuncu Yil University, Faculty of Science, Department of Chemistry, Van, Turkey.

\begin{abstract}
In this study 2,3-dicyanopyrazine based acceptor was combined with donors to obtain Donor-Acceptor type potential thermally activated delayed fluorescence (TADF) emitters (1-10). All molecules' structural and electronic properties were computed theoretically at the level of Density Functional Theory (DFT) and Time Dependent Density Functional Theory (TDDFT) with the application of three different hybrid functionals. Most of the designed structures have been found to possess the potential to be TADF compounds because they have very narrow energy gap between their first excited singlet and triplet states. As a result, 6-10 molecular pyrazine derivative has been calculated as the best candidate for the purpose. Moreover, having $0.90 \mathrm{eV}$ interfrontier molecular orbital energy band gap, compound $\mathbf{6}$ has a very strong potential to serve as an efficient OLED material.
\end{abstract}

Keywords: TADF, pyrazine, donor-acceptor, RISC, TDDFT.

\section{INTRODUCTION}

Absorption, emission and scattering occur when the light interacts with the substance. The resulting scattering is elastic Ryleigh and inelastic scattering Raman and Brillouin scattering. In the case of luminescence, absorption occurs in the light-matter interaction.

Luminescence emits some of the energy it receives in any form from any external source. Light leads to photoluminescence, a kind of absorbing luminescence occurring in matter interactions. Photoluminescence is divided into fluorescence and phosphorescence. The so-called fluorescence is a reflection of light in a certain wavelength on a set of objects. Phosphoresence is called phosphorescence after the light rays are cut off when the wavelength changes [1].

Fluorescence and phosphorescence emissions are shown in the simplified Jablonski diagram in Figure 1. Reinhoudt's empirical rule states that the intersystem crossing (ISC) process will be effective when $\Delta \mathrm{E}_{\mathrm{ST}}$ is lower than $0.6 \mathrm{eV}$ for all type of ligands [2]. It can also be explained that the delayed fluorescence phenomenon is an energy level diagram of singlet or triplet states. In the direction of the events described for each other phosphorescence. In other words, after absorption and internal energy conversion, the molecules are either at the lowest vibration level, or at the lowest vibrational levels of the first triplet state. It is possible for the specific molecules to pass from the lowest vibration level of the triplet state to the lowest vibration level of the singlet state under special experimental conditions. The energy required for this change is the conditions contained within. Under these conditions, an immediately marked singlet state will result in subsequent fluorescence [3].

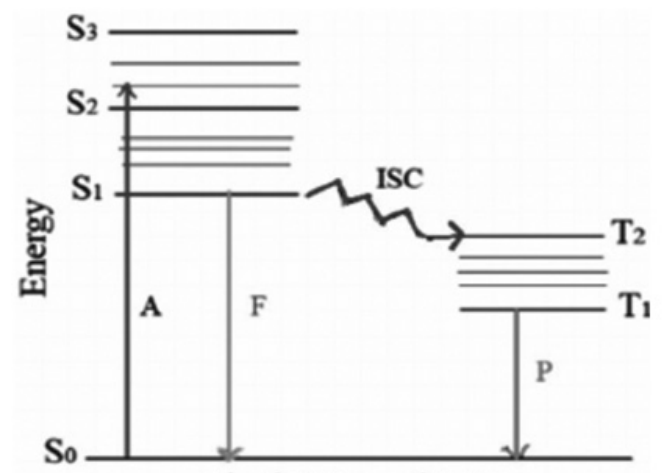

Singlet Ground State

Figure 1. A simplified Jablonski diagram showing illustration of fluorescence and phosphorescence. (A, F and $\mathrm{P}$ stand for Excitation, Fluorescence and Phosphorescence, respectively) [4].

Recently, many researchers have been working on the use of organic semiconducting materials [5-9]. Researchers have many reasons to work on organic semiconductors. These; organic semiconductors can be produced at low cost by coating techniques which can be manufactured in a very cheap and simple manner such as spin coating and printing at a time, and they can be more flexible such as being flexible and having high nonlinearity [10]. Owing to these properties, it is frequently used in technological applications such as Organic Light Emitting Diode (OLED), organic Schottky barrier diodes, Organic Field Effect Transistor (OFET), photovoltaic solar cells and spintronics in the field of electronics and optoelectronics [11].

The investigations on the EL's of organic semiconductors with conjugated $\pi$ systems are based on about 50 years ago. In 1982, coating of the anthracene with a vapor-coating technique as a thin film stepped up the steps to be made in this area by reducing the applied voltage and increasing the efficiency of the OLED device [12]

Organic Light Emitting Diodes (OLED) are devices consisting of a series of organic thin films sandwiched between two electrodes. While each organic layer is a function within the device, these devices emit light when an external voltage is applied [13]. This occurrence, called electroluminescence (EL), is defined as the space pumped from the electrodes and the electron charge carriers forming electron vacancies (excitons) in the organic semiconductors traveling under the electric field, and the resulting exciton of the couple [14$16]$.

OLEDs are not just thin and efficient - they provide the best image quality ever and they can also be made transparent, flexible, foldable and even rollable and stretchable in the future. OLEDs are used today in mobile phones, digital cameras, VR headsets, tablets, laptops and TVs. In the future, OLEDs are expected to be used in areas with curved OLED displays, wearable OLEDs, foldable OLEDs that can be used to build new mobile devices, windows or transparent OLEDs embedded in vehicle windshields, which are located on non-flat surfaces. OLEDs represent the future of technology.

2,3-Dicyanopyrazine based acceptor was combined with a series of well studied donors to obtain Donor-Acceptor type potential thermally activated delayed fluorescence emitters. In this work, a series of pyrazino [2,3-f] [1,10] phenanthroline-2,3-dicarbonitrile (Figure 2) compound was formed the structural and electronic properties were theoretically investigated at the level of Density Functional Theory.

It is expected that this work will contribute to the identification of potential candidate molecules for organic solar cells, organic light emitting diodes or fluorescent organic materials prior to the application of synthetic procedures and to illuminate synthetic organic chemistry studies.

\section{METHOD OF CALCULATION}

The ground state $\left(\mathrm{S}_{0}\right)$ geometries of all compounds were geometry optimized using DFT [17] with the Gaussian 09W [18] package program and the hybrid functional B3LYP [19,20], CAM-B3LYP [21] and WB97XD [22]. The basis set used for all atoms was $6-311+\mathrm{G}(\mathrm{d}, \mathrm{p})$ for geometry optimizations.

The low-lying triplet $(\mathrm{T})$ and singlet excited states $(\mathrm{S})$ of the compounds were relaxed to obtain their minimum energy geometries using the TDDFT. 
The vertical excitation energies and oscillator strengths were obtained for the lowest triplet and singlet transitions at the optimized ground state equilibrium geometries by using TDDFT with a series of hybrid functionals and basis sets [23]. Optimized ground state structures were utilized to obtain the electronic absorption spectra, including maximum absorption wavelengths, oscillator strengths, and main configuration assignment by using TDDFT. Although there exists some exceptions, information in the literature suggest that the analysis of the excitation energies with PBE0, wB97XD and CAM-B3LYP functionals predict the best agreement with the experimental data [24]. Therefore, for TDDFT computations B3LYP/6-311+G(d,p), CAM-B3LYP/6-311+G(d,p), WB97XD /6-311+G(d,p) methods have been applied and the results have been compared.

Calculation were performed on a HP420WS desktop computer with Intel Xeon ${ }^{\circledR}$ CPU E5-1650. Calculations are carried out with high performance server systems (work station) over the WINDOWS operating system.

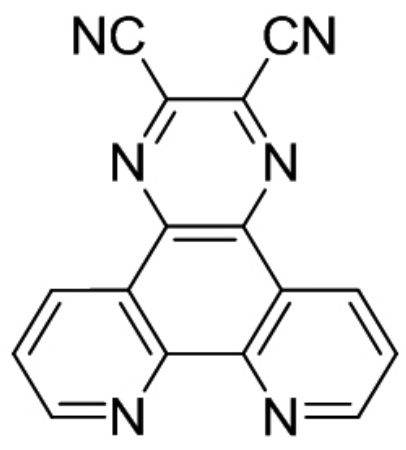

Figure 2. Structure of the parent compound (pyrazino[2,3-f][1,10] phenanthroline-2,3-dicarbonitrile)

\section{RESULTS AND DISCUSSION}

Economically viable for large-scale power generation based on environmentally green materials forces scientists to search for novel ideas and applications. Organic semiconductor materials are among the cheaper alternatives. Therefore, TADF emitters have drawn much attention and many novel compounds with this behaviour have been synthesized [25-29].

The idea of the present study emerged from the extensive spectroscopic investigations of the parent pyrazine compound performed in the literature [3032]. Containig a well acceptor moiety in its structure, combination of 1 with donor units may produce potential TADF compounds. In addition, by design modification, it is possible to spatially separate the highest occupied molecular orbital (HOMO) and lowest unoccupied molecular orbital (LUMO), causing a decrease of the energy gap $\Delta \mathrm{E}_{\mathrm{ST}}$ between the lowest excited singlet $\left(\mathrm{S}_{1}\right)$ and triplet $\left(\mathrm{T}_{1}\right)$ state. It is thus possible to enhance the fluorescence efficiency of OLEDs by an increase. A series of Donor-Acceptor (D-A) type pyrazino[2,3-f] $[1,10]$ phenanthroline-2,3-dicarbonitrile [33] derivatives are designed in order to suggest potential TADF emitters in light with the information in the literature. The pyrazine fused phenanthroline moiety with two cyano groups attached (pyrazino[2,3-f][1,10]phenanthroline-2,3-dicarbonitrile) (1) was the acceptor, benzene (2), biphenyl (3), anthracene (4), pyrene (5), quinolizine (6), carbazole (7), dihydroacridine (8), phenoxazine (9), triphenylamine (10) were donor compartments (Figure 3 ).

All molecules' structural and electronic properties were computed theoretically at the level of Density Functional Theory (DFT) and Time Dependent Density Functional Theory (TDDFT) with the application of three different hybrid functionals

Gas-phase geometry optimizations of all structures were first performed using the MM2 method and the subsequent semi-empirical PM3 using the consistent molecular orbital (SCFMO) method. For each compound, vibrational analyses were carried out using the same basis set employed in the corresponding geometry optimizations. Normal mode analysis for each structure did not result in any negative frequencies in all methods. Indicating that the structure of each molecule corresponds to at least a local minimum on the potential energy surface [34]. The normal mode analysis was performed for $3 \mathrm{~N}-6$ vibrational degrees of freedom, with $\mathrm{N}$ being the number of atoms in the molecule.

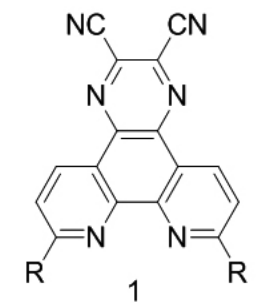

$R$ :<smiles>Cc1ccccc1</smiles>

2

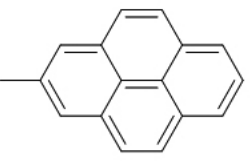

5<smiles>CN1c2ccccc2C(C)(C)c2ccccc21</smiles>

8

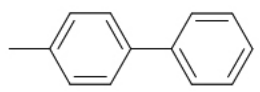

3<smiles>CC1=CC2C=CCC3=CC=CC(=C1)N32</smiles>

6<smiles>CN1c2ccccc2Oc2ccccc21</smiles>

9<smiles>Cc1c2ccccc2cc2ccccc12</smiles>

4<smiles>[3H]c1ccc(N(c2ccccc2)c2ccccc2)cc1</smiles>

10

Figure 3. Structures of potential candidate TADF compounds

\subsection{Semiconductor Properties}

Frontier molecular orbital energies of the compounds were calculated at the level of B3LYP/6-311+G(d,p) in DFT method (Table 1). The electronic structure of all organic semiconductors is based on the conjugation of $\pi$-electrons. The band gap $\left(\Delta \mathrm{E}=\mathrm{E}_{\mathrm{Luo}}-\mathrm{E}_{\mathrm{Homo}}\right)$ of semiconductor materials ranges from 0.5 to $4.0 \mathrm{eV}$ [35]. The calculated $\Delta \mathrm{E}$ values of the molecules are below $4 \mathrm{eV}$. Compound $\mathbf{1}$ (parent compound without any donor units attached) had a band gap of $4.06 \mathrm{eV}$ and can be considered as an insulator. This band gap was narrowed with the donor units attached. For this reason, all compounds have the property of being semiconductor material. The value of $\Delta \mathrm{E}$ is the narrowest for compound $\mathbf{6}$ therefore, it may be considered as the most potential OLED material.

The ground state geometry optimized structure and 3D-frontier molecular orbital energy diagrams of the compounds are given in Table 2 . The diagrams for HOMO and LUMO provide information about the reactivity of the compounds. HOMO shows basicity, while LUMO gives the acidity property of the system. Investigation into frontier molecular orbitals is very considerable. It is also important to know which atoms contribute to these orbitals. So, the reactivity centers are determined. For the compounds to be potential candidates for TADF, it is critical to possess separate HOMO and LUMO to give small exchange energies [36-38]. The HOMO and LUMO orbitals have been separated on the donor and acceptor parts of the system (Table 2). The HOMOs of D-A structures have distributed on the donor parts while the LUMOs have localized over the acceptor core, and have composed of highly electronwithdrawing cyano units together with the pyrazine. 
Table 1. Results of calculations (All data are in $\mathrm{eV}$ ).

\begin{tabular}{|c|c|c|c|c|c|c|}
\hline \multirow{2}{*}{ Compound } & \multicolumn{3}{|c|}{ DFT } & \multicolumn{3}{c|}{ TDDFT $\left(\Delta \boldsymbol{E}_{\text {ST }}\right)$} \\
\cline { 2 - 7 } & \multicolumn{2}{|c}{ B3LYP/6-311+(d,p) } & B3LYP & CAM-B3LYP & WB97XD \\
\cline { 2 - 7 } & HOMO & LUMO & $\boldsymbol{\Delta} \boldsymbol{E}$ & $\mathbf{6 - 3 1 1 + ( d , p )}$ & $\mathbf{6 - 3 1 1 + ( d , p )}$ & $\mathbf{6 - 3 1 1 + ( d , p )}$ \\
\hline $\mathbf{1}$ & -7.47 & -3.41 & 4.06 & 0.6055 & 0.6424 & 0.6296 \\
\hline $\mathbf{2}$ & $-6,77$ & -3.28 & 3.49 & 0.5832 & 0.4968 & 0.4921 \\
\hline $\mathbf{3}$ & -6.46 & -3.41 & 3.05 & 0.0481 & 0.5929 & 0.5372 \\
\hline $\mathbf{4}$ & -5.66 & -3.33 & 2.33 & 0.0012 & 0.6004 & 0.6535 \\
\hline $\mathbf{5}$ & -5.86 & -3.28 & 2.58 & 0.0568 & 0.9779 & 0.9973 \\
\hline $\mathbf{6}$ & -4.29 & -3.39 & 0.90 & 0.0395 & 0.2966 & 0.2747 \\
\hline $\mathbf{7}$ & -5.81 & -3.07 & 2.74 & 0.1710 & 0.3376 & 0.3377 \\
\hline $\mathbf{8}$ & -5.62 & -2.86 & 2.76 & 0.2338 & 0.1263 & 0.1769 \\
\hline $\mathbf{9}$ & -5.45 & -2.93 & 2.52 & 0.1874 & 0.0623 & 0.1795 \\
\hline $\mathbf{1 0}$ & -5.45 & -3.08 & 2.37 & 0.2001 & 0.2812 & 0.2664 \\
\hline
\end{tabular}

In phenanthroline pyrazine compound (1), both HOMO and LUMO have distributed over the structure. The reason for this is that the parent compound $\mathbf{1}$ is a rigid planar structure with conjugated fused rings and cyano groups. For the purpose of be able to achieve succesful separation of the frontier molecular orbitals, benzene (2) and biphenyl (3) [39] substitutions were done on each side of the phenanthroline part of the parent compound (Table 2). The geometry optimized structures of $\mathbf{2}$ and $\mathbf{3}$ resulted in a tilted structure however; well separated HOMO and LUMO could not be observed due to low donor ability of the benzene. In addition, HOMO and LUMO energy levels have not changed enough for the duo, to possess better semiconducting ability, either.

Anthracene (4) [40], pyrene (5) [41], quinolizine (6) [42], carbazole (7) [43], acridine (8) [44], pheoxazine (9) [45] and triphenylamine (10) [46] based OLED and TADF systems have been widely investigated in the literature. Therefore, combination of each of these donors with the parent compound may result in potential candidates for OLED and TADF compounds. The deviations from the planarity (donor-acceptor dihedral angles) for compounds 4-10 have allowed the HOMO-LUMO distribution to be well separated on the system. For compounds 4-10, the HOMOs are placed entirely in the donor moiety and the LUMOs are located in the donor moiety, thus creating good semiconductor materials with potential use in OLED devices.

In the energy point of view, HOMO-LUMO energy gaps $(\mathrm{Eg})$ for 4-10 change between $0.90 \mathrm{eV}$ to $2.76 \mathrm{eV}$ indicating very successful design of D-A type compounds. Potential use of compound $\mathbf{1}$ as a semiconductor material could be sucessfully increased by modification with the combination with strong donor groups. Among the studied D-A compounds, 6 (pyrazinophenanthroline-dicarbonitrile and quinolizine combination) has got the narrowest interfrontier band gap with $0.90 \mathrm{eV}$, which makes it a very important candidate as an OLED.

\subsection{TADF Properties}

Thermally activated delayed fluorescence (TADF) has attracted significant attention as the emission mechanism in molecules used in organic lightemitting diodes (OLEDs) [25]. TADF OLEDs utilize fluorescence via reverse intersystem crossing (RISC) from the triplet state, $\mathrm{T}_{1}$, as well as fluorescence from the singlet excited state, $\mathrm{S}_{1}$, providing a theoretical quantum efficiency of $100 \%$. In order to make RISC process possible in a molecule, the energy difference between $\mathrm{S}_{1}$ and $\mathrm{T}_{1}, \Delta E_{\mathrm{ST}}$, must be small enough that the RISC energy barrier can be overcome through thermal excitation (Figure 4).

Therefore, one of the most important considerations when designing TADF molecules is to achieve a small energy gap between $S_{1}$ and $T_{1}$ excited states. This requirement is met only when the lowest energy transition has low singlet-triplet exchange energy [47]. Therefore, the current trends in research on new TADF emitters are mainly focused on intramolecular donor-receptor (D-A) type molecules [48]. Appropriate donor-acceptor parts have to be chosen attentively to obtain full-color TADF molecules, with their HOMO and LUMO must be localized in different regions. To achieve details about the geometric and electronic structures of molecules 1-10 TDDFT calculations were made at the B3LYP/6-31+G(d,p), CAM-B3LYP/6-311+G(d,p), WB97XD /6-311+G(d,p) level. The HOMO, LUMO energies and the energy gap between singlet- and triplet-excited states for compounds 1-10 are given in Table 1.

Looking at the table, the separation of the frontier molecular orbitals results in narrower $\Delta \mathrm{E}_{\mathrm{ST}}$ values. $\Delta \mathrm{E}_{\mathrm{ST}}$ values for compound 1 were calculated as 0.6424 and $0.6296 \mathrm{eV}$ with CAM-B3LYP/6-311+G(d,p) and WB97XD/6$311+\mathrm{G}(\mathrm{d}, \mathrm{p})$, respectively. The $\Delta \mathrm{E}_{\mathrm{ST}}$ values for $\mathbf{2}$ and $\mathbf{3}$ slightly smaller from the parent but still needed to be improved. Though anthracene and pyrene derivatives (4 and 5) have separate HOMO-LUMO distribution and twisted, values of $\Delta \mathrm{E}_{\mathrm{ST}}$ were calculated quite high. Since $\Delta \mathrm{E}_{\mathrm{ST}}$ values $\leq 0.50 \mathrm{eV}$ are considered to be productive for TADF potential, compounds 6-10 have been found to be best candidates for TADF emitters. Compounds 6-10 have been calculated to possess very well separated HOMO-LUMO distribution and twisted geometry together with very close $\mathrm{T}_{1}$ and $\mathrm{S}_{1}$ levels (according to all levels of computations). Thus, they can be considered the most potential candidates for TADF emitters among the present structures. Thus, the $\Delta \mathrm{E}_{\mathrm{S}}$ values predicted by the TDDFT calculations are small enough for thermal repopulation of the $S_{1}$ state via $T_{1} \rightarrow S_{1}$ reverse intersystem crossing (RISC) for almost all of the compounds, but especially for 6-10. From among all calculated molecules, compound $\mathbf{6}$ might suggest the highest potential as TADF emitters as it possesses narrow $\mathrm{S}_{1}-\mathrm{T}_{1}$ energy range and best separated HOMO and LUMO diagrams. The calculated lowest energized excited states given in Table 1 can be described by the HOMO-LUMO transition corresponding to an intramolecular charge transfer (ICT) with little change in energy.

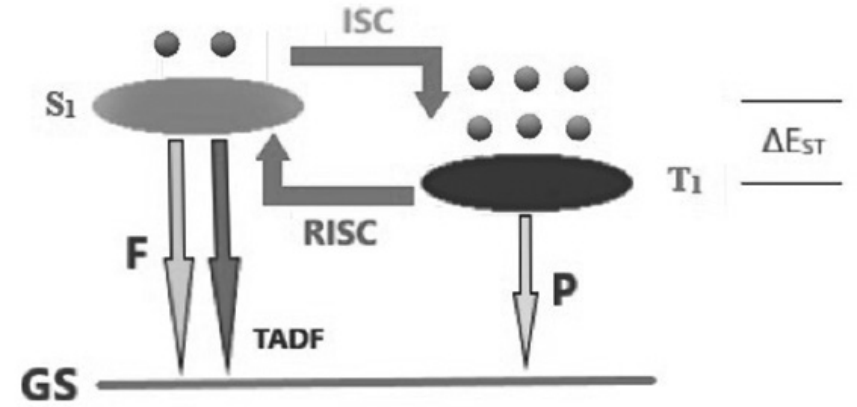

Figure 4. Illustration for ISC and RISC

\subsection{NLO Properties}

Nonlinear Optic (NLO) effects emerge from the interactions of electromagnetic fields in various media to generate new fields changed in phase, frequency, amplitude or other diffusion characteristics from the incident fields. NLO materials have been widely investigated by researchers due to their importance in applicability as the key functions of frequency shifting, optical logic, optical switching, optical modulation and optical memory for the upcoming technologies in areas of telecommunications, signaling and optical interconnections [49-52].

A Taylor series expansion of the total dipole moment, $\mu_{\text {tot }}$, (Eq. 1) induced by the field represents the NLO response of an isolated molecule in an electric 
field $\mathrm{E}_{\mathrm{i}}(\omega)$ :

$$
\mu_{\mathrm{tot}}=\mu_{0}+\alpha_{\mathrm{ij}} \mathrm{E}_{\mathrm{j}}+\beta_{\mathrm{ijk}} \mathrm{E}_{\mathrm{jk}}+\ldots
$$

where $\alpha, \mu_{0}$ and $\beta_{\mathrm{ijk}}$ are linear polarizability, the permanent dipole moment and the first hyperpolarizability tensor, respectively. The isotropic (or average) linear polarizability can be calculated by equation (2) [53]:

$$
\alpha_{\mathrm{tot}}=\left(\alpha_{\mathrm{xx}}+\alpha_{\mathrm{yy}}+\alpha_{\mathrm{zz}}\right) / 3
$$

First hyperpolarizability is a third degree tensor that is represented by $3 \times 3$ $x 3$ matrix. The 27 elements of the $3 \mathrm{D}$ matrix can be reduced to 10 components due to the Kleinman symmetry [53] such that $\beta_{\mathrm{xyy}}=\beta_{\mathrm{yxy}}=\beta_{\mathrm{yyx}}=\beta_{\mathrm{yyz}}=\beta_{\mathrm{yzy}}=$ $\left.\beta_{\mathrm{zyy}} ; \ldots\right)$. The output file of a computation in Gaussian 09 provides 10 values of this matrix as $\beta, \beta, \beta, \beta, \beta, \beta, \beta, \beta, \beta$, and $\beta$, respectively. The components of the first hyperpolarizability can be calculated using the following equation (Eq. 3) [54]:

$$
\beta_{\mathrm{i}}=\beta_{\mathrm{iii}}+1 / 3 \Sigma\left(\beta_{\mathrm{ijj}}+\beta_{\mathrm{jij}}+\beta_{\mathrm{jij}}\right)
$$

The magnitude of $\beta_{\text {tot }}$ from Gaussian program output can be calculated by Eq. 4.

$$
\beta_{\mathrm{tot}}=\left[\left(\beta_{\mathrm{xxx}}+\beta_{\mathrm{xyy}}+\beta_{\mathrm{xzz}}\right)^{2}+\left(\beta_{\mathrm{yyy}}+\beta_{\mathrm{yzz}}+\beta_{\mathrm{yxx}}\right)^{2}+\left(\beta_{\mathrm{zzz}}+\beta_{\mathrm{zxx}}+\beta_{\mathrm{zyy}}\right)^{2}\right]^{1 / 2}
$$

The calculations of the total molecular dipole moment $\left(\mu_{\text {oto }}\right)$, linear polarizability $\left(\alpha_{\text {tot }}\right)$ and hyperpolarizability $\left(\beta_{\text {tot }}\right)$ from the Gaussian output were explained in a previous work [55], and DFT has been widely used as an effective method to compute the properties of NLO materials [56]. The electronic dipole moment $\mu_{\text {tot }}$, polarizability $\alpha_{\text {tot }}$ and the hyperpolarizability $\beta_{\text {to }}$ data of all compounds were calculated at the B3LYP/6-311+G(d,p) level of theory using the Gaussian 09 package; results are given in Table 3.

Table 2. Ground state geometry (GSG), frontier molecular orbital energy diagrams (HOMO and LUMO) and dihedral angles (DA) of the compounds.

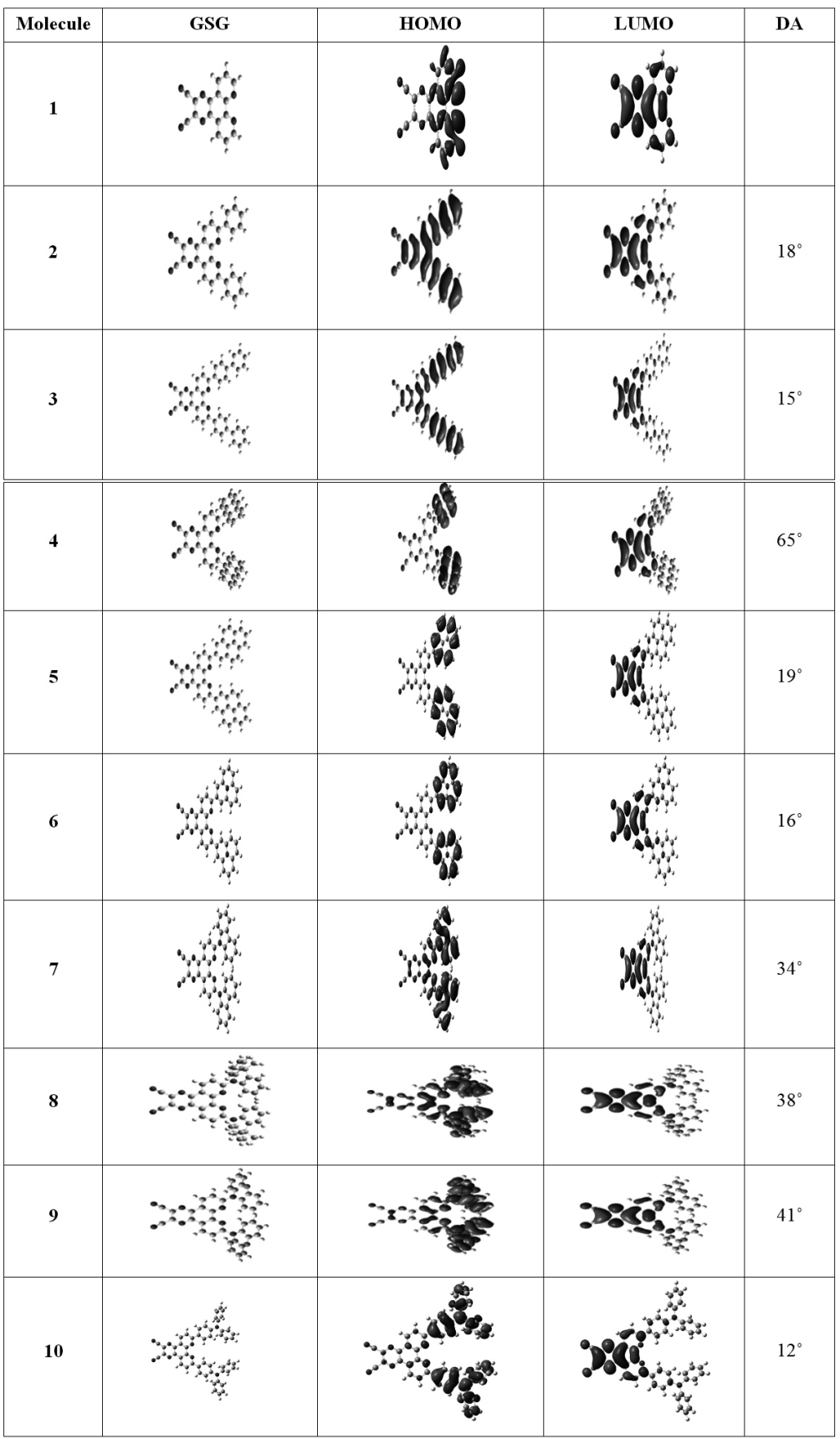


Table 3. The calculated dipole moment $\mu$ (Debye), the average polarizability $\alpha_{\text {tot }}\left(\AA^{3}\right)$ and first hyperpolarizability $\beta_{\text {tot }}\left(\times 10^{-30} \mathrm{~cm}^{5} / \mathrm{esu}\right)$ for the compounds.

\begin{tabular}{|c|c|c|c|}
\hline Compound & $\begin{array}{c}\text { Dipole } \\
\text { Moment } \\
\left(\boldsymbol{\mu}_{\text {tot }}\right)\end{array}$ & $\begin{array}{c}\text { Average } \\
\text { Polarizability } \\
\left(\boldsymbol{\alpha}_{\text {tot }}\right)\end{array}$ & $\begin{array}{c}\text { First } \\
\text { Hyperpolarizability } \\
\left(\boldsymbol{\beta}_{\text {tot }}\right)\end{array}$ \\
\hline 1 & 5.57 & 36.54 & 12.17 \\
\hline $\mathbf{2}$ & 8.08 & 59.30 & 95.65 \\
\hline $\mathbf{3}$ & 9.11 & 87.81 & 238.30 \\
\hline $\mathbf{4}$ & 7.33 & 87.22 & 139.97 \\
\hline $\mathbf{5}$ & 9.00 & 103.65 & 213.13 \\
\hline $\mathbf{6}$ & 7.79 & 93.84 & 610.07 \\
\hline $\mathbf{7}$ & 7.17 & 85.84 & 215.12 \\
\hline $\mathbf{8}$ & 8.90 & 94.64 & 200.04 \\
\hline $\mathbf{9}$ & 8.29 & 87.22 & 251.01 \\
\hline $\mathbf{1 0}$ & 12.13 & 123.91 & 647.70 \\
\hline
\end{tabular}

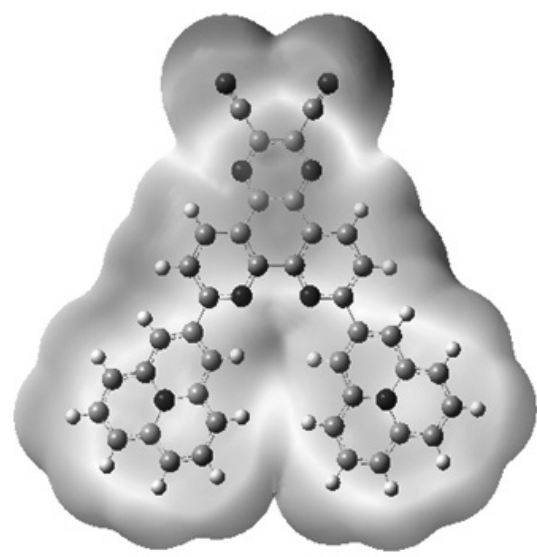

6
The calculated dipole moments vary between 5.57 (1) and 12.13 (10) Debye for the studied series. 1, itself has relatively low polarity due to competition of electron withdrawing nitrogens on one side, and cyanide units on the other side of the parent molecure. Addition of a donor group created a charge separation in the structure thus, the dipole moments for the D-A type molecules are all greater than that of compound $\mathbf{1}$. In fact, the magnitude of charges are very widely separated for $\mathbf{6}$ and $\mathbf{1 0}$ so that the greatest magnitudes of dipole moment were obtained for those compounds.

The molecular electrostatic potential (MEP) indicates the electronic density and is quite a useful descriptor in locating sites for electrophilic attack and nucleophilic reactions as well as hydrogen bonding interactions [57,58]. Moreover, the dipole moment of the system can be well observed by the indication of charge separation via coloring. Being a real physical property, MEP can be determined experimentally by diffraction or by computational methods [59].

The 3D-MEP surface counter maps were obtained for B3LYP/6$311+\mathrm{G}(\mathrm{d}, \mathrm{p})$-optimized geometries to predict reactive sites for electrophilic and nucleophilic processes for the compounds and dipole moment observation. The electrostatic potential surface of $\mathbf{6}$ is shown in Figure 5. Electrophilic reactivity regions (negative charge) are shown by red and yellow colors, while blue is an indicator of nucleophilic reactivity [59]. For the series of potential TADF compounds, the negative charge is localized on the electron withdrawing cyanide regions, as expected. The charge separation is very well observed for 10, which may be the reason for the highest magnitude dipole moment (Figure 5).

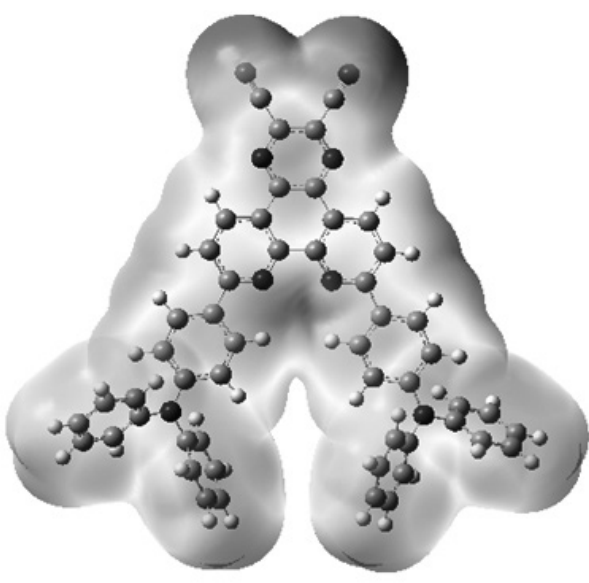

10

Figure 5. Molecular electrostatic maps of $\mathbf{6}$ and $\mathbf{1 0}$ computed at B3LYP/6-311+G(d,p) level of theory.

The average polarizability $\left(\alpha_{\text {tot }}\right)$ data are also listed in Table 3. The highest values of calculated polarizabilities are equal to $103.65 \AA^{3}$ for $\mathbf{5}$ and 123.91 $\AA^{3}$ for 10. Hyperpolarizability data $\beta_{\text {tot }}$ for all of the compounds are much greater than that of urea $\left(0.77 \times 10^{-30} \mathrm{~cm}^{5} / \mathrm{esu}\right)$ [50], which is one of the typical compounds used in research into the NLO properties of molecular systems. Therefore, it was used frequently as a threshold value for comparative studies [60]. The obtained results show that all of the compounds are good candidates of NLO materials. First order hyperpolarizability data for 1 was computed to be $12.17 \times 10^{-30} \mathrm{~cm}^{5} / \mathrm{esu}$ that of Phenanthroline was found to be $0.8 \times 10^{-30} \mathrm{~cm}^{5} / \mathrm{esu}$ [46]; thus, an increase in the conjugation path upon substitution of the $\pi$ link and other groups resulted in an increase in first hyperpolarizability. Comparison of inter-frontier energy gap data with the hyperpolarizability values is a good indicator of nonlinear properties. $\Delta \mathcal{E}$ for urea was calculated to be $8.2 \mathrm{eV}$ at the same level of DFT method, whereas the $\Delta \varepsilon$ values for the present systems vary in the range from $0.90-3.49 \mathrm{eV}$ (Table 1)

As can be seen from the $\Delta E$ (Table 1) and $\beta_{\text {tot }}$ (Table 3) values for the present compounds, there is an inverse relationship between HOMO-LUMO gap and first hyperpolarizability. In these systems, the molecular orbitals overlap to form a proper electronic conjugation, which is a marker of the intramolecular charge transfer from the electron-donating group through the $\pi$-conjugation system to the electron-withdrawing cyano group [61].

\section{CONCLUSION}

A known acceptor, that is, pyrazino[2,3-f][1,10]phenanthroline-2,3dicarbonitrile has been combined with famous donors which are often preferred for the design of potential OLED and TADF emitters. Their structural and electronic properties were computed with the application of Density Functional Theory at different levels of theory.

Among the ten designed compounds, compounds 6-10 were elected as the best candidates for TADF emitters due to their well separated HOMO-LUMO orbitals and $\Delta \mathrm{E}_{\mathrm{ST}}$ data. Moreover, compound $\mathbf{6}$ had the narrowest interfrontier molecular orbital energy gap $(\Delta E)$ since it was computed to be $0.90 \mathrm{eV}$. This is a very important indication that derivatization through addition of a donor to the acceptor system drastically decreases the HOMO-LUMO band gap. The parent pyrazino-phenanthroline-dicarbonitrile computed to have a HOMO energy level of $-7.47 \mathrm{eV}$ which was pushed up to $-4.29 \mathrm{eV}$ upon addition of quinolizine (donor unit) to form compound $\mathbf{6}$. Thus, the parent almost with an insulator behavior turned to a useful semiconductor which can be a strong candidate for OLEDs. In addition, compounds 6-10 have the potential to act as TADF emitters to increase the quantum efficiency of the OLED material since their excited state singlet-triplet energy level differences are smaller than 0.50 $\mathrm{eV}$ for all the applied methods. 


\section{REFERENCES}

[1] N.T. Kalyani, H. Swart, S.J. Dhoble, Principles and Applications of Organic Light Emitting Diodes (OLEDs). Duxford, United Kingdom, Woodhead Printing, 2017.

[2] G.F. deSa, O.L. Malta, D.C. deMello, A.M. Simas, R.L. Longo, P.A. Santa-Cruz, E.F. daSilva, Spectroscopic properties and design of highly luminescent Lanthanide coordination complexes. Coord. Chem. Rev. 2000, 196, 165-95.

[3] B.Valeur, M.N. Berberan-Santos, Molecular fluorescence: principles and applications. John Wiley and Sons, 2012.

[4] S. Basak, K. Chattopadhyay, Studies of protein folding and dynamics using single molecule fluorescence spectroscopy, Phys. Chem. Chem. Phys. 16 (2014) 11139-11149.

[5] F. Yakuphanoğlu, S. Okur, Analysis of electronic parameters and interface states of boron dispersed triethenolemine/p-Si structure by AFM, I-V, C-V-f and G/w-V-f techniques, Mikroelectronic Engineering, 87 (2010) 30-34

[6] Ö.F. Yüksel, N. Tuğluoğlu, H. Şafak, M. Kuş, The motification of Schottky barrier height of $\mathrm{Au} / \mathrm{p}$-Si Schottky devices by perylene-diimide, J. Appl. Phys. 113 (2013) 044507-044516.

[7] S. Okur, F. Yakuphanoğlu, M. Özsöz, P.K. Kadayıfçılar, Electrical and interface properties of $\mathrm{Au} / \mathrm{DNA} / \mathrm{n}-\mathrm{Si}$ organic-on-inorganic structures, Microelectr. Eng. 86 (2009) 2305-2311.

[8] R.K. Gupta, R.A. Singh, Fabrication and characteristics of Schottky diode based on composite organics semiconductor, Comp. Sci. Tech., 65 (2005) 677-681.

[9] Ş. Aydoğan, Ü. İncekara, A.R. Deniz, A Türüt, Extraction of electronic parameters of Schottky diode based on an organic Orcein, Microelectr. Eng., 87 (2010) 2525-2530.

[10] Ö. Güllü, S. Asubay, Ş. Aydoğan, A. Türüt, Electrical characterization of the Al/new fuchsin/n-Si organic-modified device, Physica E, 42 (2010) 1411-1416.

[11] I.S. Yahia, A.A. Farag, F. Yakuphanoğlu, W.A. Farooq, Temperature dependence of electronic parameters of organic Schottky diode based on fluorescein sodium salt, Synthetic Metals, 161 (2011) 881-887.

[12] P.S. Vincett, W.A. Barlow, R.A. Hann, G.G. Roberts, Electrical conduction and low voltage blue electroluminescence in vacuumdeposited organic films, Thin Solid Films, 94 (1982) 171-183.

[13] C. Binggeli, Interior Graphic Standards: Student Edition. New Jersey, Wiley, 2012

[14] Y.F. Liu, J. Feng, Y.F. Zhang, H.F. Cui, D. Yin, Y.G. Bi, J.F. Song, Q.D. Chen, H.B. Sun, Improved efficiency of indium-tin-oxide-free flexible organic light-emitting devices. Org. Electron. 15 (2014) 478-483.

[15] Q.Y. Zhang, K. Pita, S. Buddhudu, C.H. Kam, Luminescent properties of rare -earth ion doped yttrium silicate thin film phosphors for a full -colour display, J Phys D 35 (2002) 3085-3090.

[16] W. Xiaoxiao, L. Fushan, W. Wei, G. Tailiang, Flexible white phosphorescent organic light emitting diodes based on multilayered graphene/PEDOT:PSS transparent conducting film, Appl. Surf. Sci. 295 (2014) 214-218

[17] W. Kohn, L.J. Sham, Self-consistent equations including exchange and correlation effects. Phys. Rev. 140 (1965) 1133-1138.

[18] M.J. Frisch, G. W. Trucks, H. B. Schlegel, G. E. Scuseria, M. A. Robb, J. R. Cheeseman, G. Scalmani, V. Barone, B. Mennucci, G. A. Petersson, H. Nakatsuji, M. Caricato, X. Li, H. P. Hratchian, A. F. Izmaylov, J. Bloino, G. Zheng, J. L. Sonnenberg, M. Hada, M. Ehara, K. Toyota, R. Fukuda, J. Hasegawa, M. Ishida, T. Nakajima, Y. Honda, O. Kitao, H. Nakai, T. Vreven, J. A. Montgomery, Jr., J. E. Peralta, F. Ogliaro, M. Bearpark, J. J. Heyd, E. Brothers, K. N. Kudin, V. N. Staroverov, T. Keith, R. Kobayashi, J. Normand, K. Raghavachari, A. Rendell, J. C. Burant, S S. Iyengar, J. Tomasi, M. Cossi, N. Rega, J. M. Millam, M. Klene, J. E. Knox, J. B. Cross, V. Bakken, C. Adamo, J. Jaramillo, R. Gomperts, R. E. Stratmann, O. Yazyev, A. J. Austin, R. Cammi, C. Pomelli, J. W. Ochterski, R. L. Martin, K. Morokuma, V. G. Zakrzewski, G. A. Voth, P. Salvador, J. J. Dannenberg, S. Dapprich, A. D. Daniels, O. Farkas, J. B. Foresman, J. V. Ortiz, J. Cioslowski, and D. J. Fox, Gaussian 09, Revision D.01, Gaussian, Inc., Wallingford CT, 2013.

[19] A.D. Becke, Density-functional exchange-energy approximationwith correct asymptotic behavior, Phys Rev A 1988, 38, 3098-3100.

[20] C. Lee, W. Yang, R.G. Parr, Development of the Colle-Salvetti correlation energy formula into a functional of the electron density, Phys Rev B 37 (1988) 785-789.
[21] T. Yanai, D. Tew, and N. Handy, A new hybrid exchange-correlation functional using the Coulomb-attenuating method (CAM-B3LYP), Chem. Phys. Lett., 393 (2004) 51-57.

[22] J.-D. Chai and M. Head-Gordon, Long-range corrected hybrid density functionals with damped atom-atom dispersion corrections, Phys. Chem. Chem. Phys., 10 (2008) 6615-6620.

[23] M.E. Casida, C. Jamorski, K.C. Casida, D.R. Salahub, Molecular excitation energies to high-lying bound states from timedependent density-functional response theory: characterization and correction of the time-dependent local density approximation ionization threshold, J. Chem. Phys. 108 (1998) 4439-4449.

[24] S.M. Yanez, S.A. Moya, C. Zuniga, G.C. Jiron, Theoretical assessment of TD-DFT applied to a ferrocene-based complex, Comput. Theor. Chem. 1118 (2017) 65-74.

[25] A. Endo, M. Ogasawara, A. Takahashi, D. Yokoyama, Y. Kato, C. Adachi, Thermally Activated Delayed Fluorescence from Sn4+-Porphyrin Complexes and Their Application to Organic Light Emitting Diodes A Novel Mechanism for Electroluminescence. Adv. Mater. 21 (2009) 4802-4806.

[26] A. Endo, K. Sato, K. Yoshimura, T. Kai, A. Kawada, H. Miyazaki, C. Adachi, Efficient up-conversion of triplet excitons into a singlet state and its application for organic light emitting diodes, Appl. Phys. Lett. 98 (2011) 83302-83305

[27] R. Czerwieniec, J. Yu, H. Yersin, Blue-Light Emission of $\mathrm{Cu}(\mathrm{I})$ Complexes and Singlet Harvesting, Inorg. Chem. 50 (2011) 8293-8301.

[28] M.J. Leitl, F.R. Küchle, H.A. Mayer, L. Wesemann, H. Yersin, Brightly Blue and Green Emitting $\mathrm{Cu}(\mathrm{I})$ Dimers for Singlet Harvesting in OLEDs, J. Phys Chem A 117 (2013) 11823-11836.

[29] H. Uoyama, K. Goushi, K. Shizu, H. Nomura, C. Adachi, Highly efficient organic light-emitting diodes from delayed fluorescence, Nature 492 (2012) 234-238.

[30] Z. Khodaee, A. Yahyazadeh, N.O. Mahmoodi, M.A. Zanjanchi, V. Azimi, One-pot synthesis and characterization of new cuprous pyrazinoporphyrazines containing peripherally functionalized units, J. Mol. Struct. 1029 (2012) 92-97.

[31] J.L. Nishida, S. Murai, E. Fujiwara, H. Tada, M. Tomura, Y Yamashita, Preparation, Characterization, and FET Properties of Novel Dicyanopyrazinoquinoxaline Derivatives, Org. Lett. 6 (2004) 2007-2010.

[32] M.A. Ivanov, M.V. Puzyk, K.P. Balashev, Spectroscopic and Electrochemical Properties of Dichlorodiimine Complexes of $\mathrm{Au}(\mathrm{III})$ and Pt(II) with 1,4-Diazine Derivatives of o-Phenanthroline, Russ. J. Gen. Chem. 76 (2006) 843-848

[33] L. Kozlov and I. Goldberg. Hydrogen-bonding versus [pi]-[pi] stacking interactions in dipyrido[f,h]quinoxaline-6,7-dicarbonitrile and 6,7-dicyanodipyrido[f,h]quinoxalin-1-ium chloride dihydrate, Acta Cryst. 64 (2008) 498-501.

[34] Z. Turhan Irak, S. Gümüș, Heterotricyclic Compounds via Click Reaction: A Computational Study, Noble Int. J. Sci. Res. 7 (2017) 80-89.

[35] P. Atkins, T. Overton, J. Rourke, M. Weller, F. Armstrong, Shriver and Atkins Inorganic Chemistry, Fourth Edition, Oxford University Press, Oxford, 2006.

[36] T. Nakagawa, S.Y. Ku, K.T. Wong, C. Adachi, Electroluminescence based on thermally activated delayed fluorescence generated by a spirobifluorene donor-acceptor structure, Chem. Commun. 48 (2012) 9580-9582.

[37] G. Mehes, H. Nomura, Q. Zhang, T. Nakagawa, C. Adachi, Enhanced electroluminescence efficiency in a spiro-acridine derivative through thermally activated delayed fluorescence, Angew. Chem. Int. Ed. 51 (2012) 11311-11315

[38] K. Nasu, T. Nakagawa, H. Nomura, C.J. Lin, C.H. Cheng, M.R. Tseng, T. Yasuda, C. Adachi, A highly luminescent spiro-anthracenone-based organic light-emitting diode exhibiting thermally activated delayed fluorescence, Chem. Commun. 49 (2013) 10385-10387.

[39] M.L. Daly, C.A. DeRosa, C. Kerr, W.A. Morris, C.L. Fraser, Blue thermally activated delayed fluorescence from a biphenyl difluoroboron $\beta$-diketonate, RSC Adv. 6 (2016) 81631-81635.

[40] M. Aydemir, G. Haykır, A. Battal, V. Jankus, S.K. Sugunan, F.B. Dias, H. Attar, F. Türksoy, M. Tavasl, A.P. Monkman, High efficiency OLEDs based on anthracene derivatives: The impact of electron donating and withdrawing group on the performance of OLED, Org. Electr. 30 (2016) 149-157.

[41] T. Shan, Z. Gao, X. Tang, X. He, Y. Gao, J. Li, X. Sun, Y. Liu, H. Liu, B. Yang, P. Lu, Y. Ma, Highly efficient and stable pure blue nondoped organic 
light-emitting diodes at high luminance based on phenanthroimidazolepyrene derivative enabled by triplei-triplet annihilation, Dyes and Pigments 142 (2017) 189-197.

[42] D. Zhang, C. Zhao, Y. Zhang, X. Song, P. Wei, M. Cai, L. Duan, Highly efficient full-color thermally activated delayed fluorescent organic lightemitting diodes: extremely low efficiency roll-off utilizing a host with small singlet-triplet splitting. ACS App. Mater. Interfaces. 9 (2017) 4769-4777.

[43] B. Çiçek, Ü. Çalışı, M. Tavaslı, R. Tülek, A. Teke, Synthesis and optical characterization of novel carbazole Schiff bases, J. Mol. Struct. 1153 (2018) 42-47.

[44] J.A. Seo, M.S. Gong, W. Song, J.Y. Lee, Molecular Orbital Controlling Donor Moiety for High-Efficiency Thermally Activated Delayed Fluorescent Emitters, Chem. Asian J. 11 (2016) 868-873.

[45] P. Li, Y. Cui, C. Song, H. Zhang, A systematic study of phenoxazinebased organic sensitizers for solar cells, Dyes and Pigments 137 (2017) 12-23.

[46] A. Gümüș, S. Gümüș, A Computational Study on a Series of Phenanthrene and Phenanthroline Based Potential Organic Photovoltaics, Maced. J. Chem. Chem. Eng. 36 (2017) 239-249.

[47] N.J. Turro, Modern Molecular Photochemistry, University Science Books, 1991.

[48] J. Li, Q. Zhang, H. Nomura, H. Miyazaki, C. Adachi, Thermally Activated Delayed Fluorescence from $n \pi *$ to $n \pi^{*}$ up-Conversion and its Application to Organic Light- Emitting Diodes, Appl. Phys. Lett. 105 (2014) 1330113304.

[49] Y.X. Sun, Q.L. Hao, W.X. Wei, Z.X. Yu, L.D. Lu, X. Wang, Y.S. Wang, Experimental and density functional studies on 4-(3,4-dihydroxybenzylideneamino)antipyrine, and 4-(2,3,4-trihydroxybenzylideneamino)antipyrine, J. Mol. Struct.:Theochem 904 (2009) 74-82.

[50] C. Andraud, T. Brotin, C. Garcia, F. Pelle, P. Goldner, B. Bigot, A. Collet, Theoretical and experimental investigations of the nonlinear optical properties of vanillin, polyenovanillin, and bisvanillin derivatives, J. Am. Chem. Soc. 116 (1994) 2094-2102.

[51] V.M. Geskin, C. Lambert, J.L. Bredas, Origin of High Second- and Third-
Order Nonlinear Optical Response in Ammonio/Borato Diphenylpolyene Zwitterions: the Remarkable Role of Polarized Aromatic Groups, J. Am. Chem. Soc. 125 (2003) 15651-15658

52] M. Nakano, H. Fujita, M. Takahata, K. Yamaguchi, heoretical Study on Second Hyperpolarizabilities of Phenylacetylene Dendrimer: Toward an Understanding of Structure-Property Relation in NLO Responses of Fractal Antenna Dendrimers, J. Am. Chem. Soc. 124 (2002) 9648-9655.

[53] D. Sajan, H. Joe, V.S. Jayakumar, J. Zaleski, Structural and electronic contributions to hyperpolarizability in methyl p-hydroxy benzoate, J. Mol. Struct. 785 (2006) 43-53.

[54] R. Zhang, B. Du, G. Sun, Y.X. Sun, Experimental and theoretical studies on o-, m- and p-chlorobenzylideneaminoantipyrines, Spectrochim. Acta A 75 (2010) 1115-1124.

[55] D.A. Kleinman, Nonlinear Dielectric Polarization in Optical Media, Phys. Rev. 126 (1962) 1977-1979.

[56] K.S. Thanthiriwatte, K.M. Nalin de Silva, Non-linear optical properties of novel fluorenyl derivatives - ab initio quantum chemical calculations, J. Mol. Struct.:Theochem 617 (2002) 169-175.

[57] H. Tanak, K. Pawlus, M.K. Marchewka, A. Pietraszko, Structural, vibrational and theoretical studies of anilinium trichloroacetate: New hydrogen bonded molecular crystal with nonlinear optical properties, Spectrochim. Acta Part A 118 (2014) 82-93.

[58] E. Scrocco, J. Tomasi, Topics in Current Chemistry, vol. 7, Springer, Berlin, 1973.

[59] F.J. Luque, J.M. Lopez, M. Orozco, Perspective on Electrostatic interactions of a solute with a continuum. A direct utilization of ab initio molecular potentials for the prevision of solvent effects, Theor. Chem. Acc. 103 (2000) 343-345.

60] H. Tanak, A.A. Agar, O. Buyukgungor, Experimental (XRD, FT-IR and UV-Vis) and theoretical modeling studies of Schiff base (E)-N'-((5nitrothiophen-2-yl)methylene)-2-phenoxyaniline, Spectrochim. Acta Part A 118 (2014) 672-682.

[61] H. Tanak, Density functional computational studies on 2-[(2,4-Dimethylphenyl)iminomethyl]-3,5-dimethoxyphenol, Int. J. Quant. Chem. 112 (2012) 2392-2402. 